addition to coal-cutting machines, which had been devised to dispense with powder, or render its employment safe. The use of compre sed air had been attended by some measure of success, and the dispersion of water, used as tamping, by the explosion of a powder charge in the form of a spray, had been shown to have frequently, thongh not reliably, the effect of drowning the flame developed by the explosion. The employment of water-columns, by which the force developed by the detonation of dynamite was uniformly transmitted throughout the entire length of the hole, had been proved, by experiments in coal-mines in Lancashire, and special test-experiments at Cardiff, to render that material very suitable for coal-getting, and at the same time to render blasting possible without liberation of flame. Lastly, the employment of cylinders or cartridges of compressed quicklime, according to a simple system elaborated by Professors Smith and Moore, was referred to as ranking before all other methods of getting coal, yet proposed, in point of simplicity, cost, and above all, safety, and the lecturer described operations witnessed by himself with this system of coal-getting at Shipley Collieries. In concluding, Mr. Abel exhorted those intecested in, or entrusted with the working of coal-mines, to spare no pains to test rigorously and fairly the merits of any processes or methods of affording promise of dispensing with the employment of powder in the ordinary way, and thus of securing protection to the miner against combined dangers of fire-damp and dust.

\section{THE INFLUENCE OF TEMPERATURE ON} CERTAIN SEEDS

$\mathrm{O}^{\mathrm{N}}$ regarding seeds of our hardy trees which are sown in autumn, and which do not germinate before the return of spring, we feel forced to admit that however the other conditions may vary, the cause which causes the germination in the commencement of the fine weather is the rise in the temperature, and one is equally tempted to think that the higher the temperature, as long as this rise does not equal that which would destroy the seeds, the more active and pronounced would be the germination. Nevertheless this is not by any means always the case, at any rate in the seeds of the walnut and almond trees. Anxious to germinate some of these seeds in winter, Prof. H. Baillon thought to obtain a more rapid development in a warm house, in which the temperature varied within the twenty-four hour from $15^{\circ}$ to $25^{\circ}(59-77 \mathrm{~F}$.), than in a cool huuse in which during the same time the temperature varied between $5^{\circ}$ and $15^{\circ}(41-$ $59 \mathrm{~F}$.$) , but the trial proved a failure. In the cool-house, in the$ course of six weeks, the walnuts had stems of about two decimetres in height, whereas the most advanced of those in the warm house had only stems of from two to three centimetres in the fully developed leaves. The experiment was several times repeated. The same quality of earth, and the same quantity of water was used, and the results were the same. After a space of two aud a half months the greater part of the nuts sown in the warm house had only roots occasionally well developed, but little or no caulome outside the fruit. Moreover, the greater part of the walnuts which germinated in a house, where there was good bottom-heat, had roots which did not behave like those of walnuts, germinating in the cool house and without bottom heat, the tap root of the latter grew well in length before any egress of the plumule, whereas the tap-roots of those grown in the warm house were early arrested in their development, and this through growing in a very friable soil, consisting of moist sawdust, much less resisting than the sand or the earth of the cool-house, in which the tap-roots developed so well. This was very nearly the same with the almonds, and would seem to point to the fact that in the case of some seeds there is no advantage to be gained by forcing them. Some, like Eranthis hiemalis, at whatever period they are sown in the open air, will develop themselves at a fixed time, as it does in January ( $H$. Baillon in No. 39 of the Bulletin Periodique de la Soc Linn. de Paris, January, 1882.)

\section{UNIVERSITY AND EDUCATIONAL}

\section{INTELLIGENCE}

Prof. Henry Alleyne Nicholsos has been appointed to the chair of Natural History in Aberde.n, vacant by the removal of Prof. Cossar Ewart to Edinburgh.

Dr. SORBY, F.R.S., has been elected president of Firth College, Sheffield.
THE Nottingham University College Committee have appointed Mr. Wm. Garnett, of St. John's College, Cambridge, to the Professorship of Mathematics and Physics, at the College, vacant by the resignation of Prof. Fleming.

\section{SCIENTIFIC SERIALS}

American Fournal of Science, April.-The wings of pterodactyles, by O. C. Marsh.-Sandstones having the grains in part quartz crystals, by A. A. Young.-Notes on American earthquakes, No. II, by C. J. Rockwood. -Notes on the electromagnetic theory of light, No. I, by J. W. Gibbs.-The "timber line," by H. Gannett.-Simple method for calibrating thermometers, by S. W. Holman. - Notice of Fisher's " Physics of the Earth's Crust," by C. Dutton.- - Yhysiological optics, No. III., by W. L. Stevens. - Great dyke of Foyaite or Elœolite-syenite in North-Western New Jersey, by B. K. Emerson.--Notice of the remarkable marine fauna occupying the outer bank off the southern coast of New England, No. 5I, by A. E. Verrill.Determination of phosphorus in iron, by J. L. Smith.

Fournal a'e Physique, March.-On the electro-chemical equivalent of water, by M. Mascart.- Studies on the psychrometer, by M. Angot.-Electric Lighting (concluded), by M. Foussereau. Determination of the ventral segments of sonorous tubes by means of manometric flames, by M. Hurion.-Compensator for measuring electromotive forces, by M. Slouguinoff.-On phosphorographs of the solar spectrum, by M. Becquerel.

A pril.-On a simple law relative to natural magnetic double circular refraction, by M. Cornu. - Determination of the illuminating power of simple radiations, by MM. Crova and Lagarde.-Measurement of potentials corresponding to determinate explosive distances, by M. Baille.--Study on the combustion of explosive gaseous mixtures, by MM. Mallard and Le Chatelier. - New dry sensitive thermometer, by M. Michelson.

Sitzungsberichte der physkalisch-medicinischen Societät zu Erlangen, I3 Heft, November, 1880, to August, 1881.-On the action of the milk-juice of Ficus carica, by A. Hansen.-On the artificial production of double-formations in chickens, by L. Gerlach.-On intra-thoracic pressure, by J. Rosenthal.-On the law of dispersion, by E. Lommel.-A polarisation apparatus from platincyanide of magnesium, by the same.-The germinal plates of Planaria, by E. Selenka.-Contributions to the theory of binary forms, by M. Noether.-Observations on the compo sition ard exchange of material of the electrical organ in the torpedo, by $\mathrm{T}$. Weyl.- On a new way of permanently fixing small anatomical objects for the purposes of demonstration, and preserving them without use of alcohol, ky L. Gerlach.-On the compression of drugs, by J. Rosenthal.-On the influence of chemical agents on the amount of assimilation of green plants, by T. Weyl.

Rivista Scientifico-Industriale e Giornale del Naturalista, January 31.-Mode of rendering the Holtz machine more active, by C. Marangoni.- The radiometer and school experiments, by C. Rovelli.-On a Querquedula new to Italy, by A. Fiori.-New applications of the pneumatic method for rapid desiccation of large Orthoptera, \&c., by P. Stefanelli.-Preparation of Hemiptera, by G. Cavanna.-Contribution to the study of anthropology of the Southern Provinces, by M. del Lupo.

February 28.-Nephoscope of P. F. Cecchi.-On the synthesis of various organic acids, by Drs. Bartoli and Papasogli, through electrolysis of water and of acid on alkaline, \&c., solutions with carbon-electrodes, by P. Guasti.-Differential apparatus for determining the ozone in air, by D. Tommasi.-Observations on the habits and the development of Aschna cyanta, Muill., by P. Stefanelli.

March I 5.-On Lebia turcica, Fab., by F. Piccioli.--Lombard palæontology; fossil fauna of Lombardy, by A. Stoppani.

Racle Istituto Lombardo di Scienze e Lettere. Rendiconti, vol. xv. fasc. iv.-On some fossil insects of Lombardy, by F. Sordelli.Some theorems on the degenerate forms of ellipsoid of Culmann, by G. Jung.- The double quadratic transformation of space (continued), by F. Aschieri.-Geometrical construction of the universal transformation of the third order, by $\mathrm{E}$. Bertini.

Fasc. v. - Reduction of integrals of algebraic functions to integrals of rational functions, by C. Formenti, - What are the most simple and sure means of radical cure of hemorrhoidal varices? by A. Scarenzio.-Aberrations of the sexual sentiment 